\title{
POR UMA ÉTICA AMBIENTAL PARA A AMÉRICA LATINA E CARIBE PÓS COVID-19
}

\author{
Vilmar Alves Pereira ${ }^{1}$ \\ Márcia Pereira da Silva²
}

\begin{abstract}
RESUMO: Este ensaio tem por objetivo pensar possibilidades éticas para América Latina e Caribe no contexto pós COVID-19. Trata-se de um olhar a partir do campo dos Fundamentos da Educação Ambiental. A partir de um horizonte hermenêutico existencialista, o ensaio recupera num primeiro momento uma breve contextualização histórica da ética acenando para o cenário atual de esgotamento da forma de proceder da ética antropocêntrica capitalista; a seguir apresenta alguns dilemas éticos postos pela atual conjuntura do COVID-19 e a reivindicação da Ética Ambiental; posteriormente apresenta algumas opões éticas para nosso continente. $O$ estudo chama a atenção para a necessidade de ruptura com o modo de produção capitalista e adoção do ecossocialismo, abandono da matriz energética do petróleo e do carvão, valorização dos povos marginalizados, defesa dos recursos naturais, resistência mediante as ameaças a democracia, enfrentamento das mudanças climáticas, perspectivas da Ontologia da Esperança e da Ecologia Cosmocena como horizonte ético para uma América pós COVID-19.
\end{abstract}

Palavras-chave: Ética Ambiental; Sociedade; Pós COVID-19.

ABSTRACT: This essay aims to think about ethical possibilities for Latin America and the Caribbean in the post-COVID-19 context. It is a look from the field of Fundamentals of Environmental Education. From an existentialist hermeneutic horizon, the essay recovers, at first, a brief historical contextualization of ethics, pointing to the current scenario of exhaustion of the way of proceeding from capitalist anthropocentric ethics; the following presents some ethical dilemmas posed by the current situation of COVID-19 and the claim of Environmental Ethics; later it presents some ethical options for our continent. The study draws attention to the need to break with the capitalist mode of production and adopt ecosocialism, abandoning the energy matrix of oil and coal, valuing marginalized peoples, defending natural resources, resisting threats to democracy, facing up to climate change, perspectives from the Ontology of Hope and Cosmocene Ecology as an ethical horizon for a post-COVID-19 America.

Keywords: Ethics Environmental; Society; COVID-19 Powders.

\footnotetext{
1 Universidade Federal do Rio Grande, Rio Grande, RS. E-mail: vilmar1972@gmail.com

2 Associação Rio Grandina de Umbanda e Religiões de Matriz Africana - ARUTEMA, RS.

E-mail: marciacoracoralina@yahoo.com.br
} 


\section{Introdução}

O cenário vivido em nossos dias na América Latina e Caribe e em todo o mundo é por certo carregado de questões fundamentais, e diante da crise generalizada de ética, é fundamental olharmos para originalidade da ética, que segundo Boff $(2011$, p.9) 'é um conjunto de valores e princípios, de inspirações $e$ indicações que vale para todos e se ancora na nossa própria humanidade'. Sob esse olhar necessariamente precisamos iniciar nosso pensar histórico sobre a ética nos questionando se de fato esses valores e princípios são para todos igualmente? Até onde agimos nos guiando por eles? Qual o alcance que a ética possui no sentido de garantirmos um futuro melhor com vida digna em continentes onde a vida se encontra ainda mais ameaçada pelas escolhas políticas que fazemos numa sociedade pós COVID-19?

Precisamos então, em primeira instancia, pensar sobre a etimologia da palavra ética para, posteriormente realizarmos a tentativa compreensiva do porquê temos uma crise ética e, efetivamente, como essa crise se materializou em nossas ações e em nosso modo de vida. A ética entendida como ciência da conduta tem desde a Antiguidade duas concepções distintas, que, embora aparentemente soem idênticas, se distanciam quando começam a conceituar a ideia de bem, de bom.

A primeira considera a ética como a ciência orientadora da conduta da humanidade e dos meios que essa mesma humanidade pode utilizar-se para ser considerada suas decisões e ações éticas. A segunda concebe a ética como a ciência que move a conduta e tem em vista uma disciplinar desta conduta. Essas duas concepções se 'entremesclaram de várias maneiras na Antiguidade e no mundo moderno' (ABBAGNANO,2015.444).

Porém a ambiguidade dessas duas concepções se torna evidente quando tratam do bem. No intuito de estabelecer uma rede de compreensões filosóficas que estabeleceram em torno da ética, elaboramos uma rede de conexões que buscam apresentar essa trajetória da ética enquanto ciência, compreendendo que não é possível falar de crise ética sem lançar esse olhar para trás (Figura 1). 


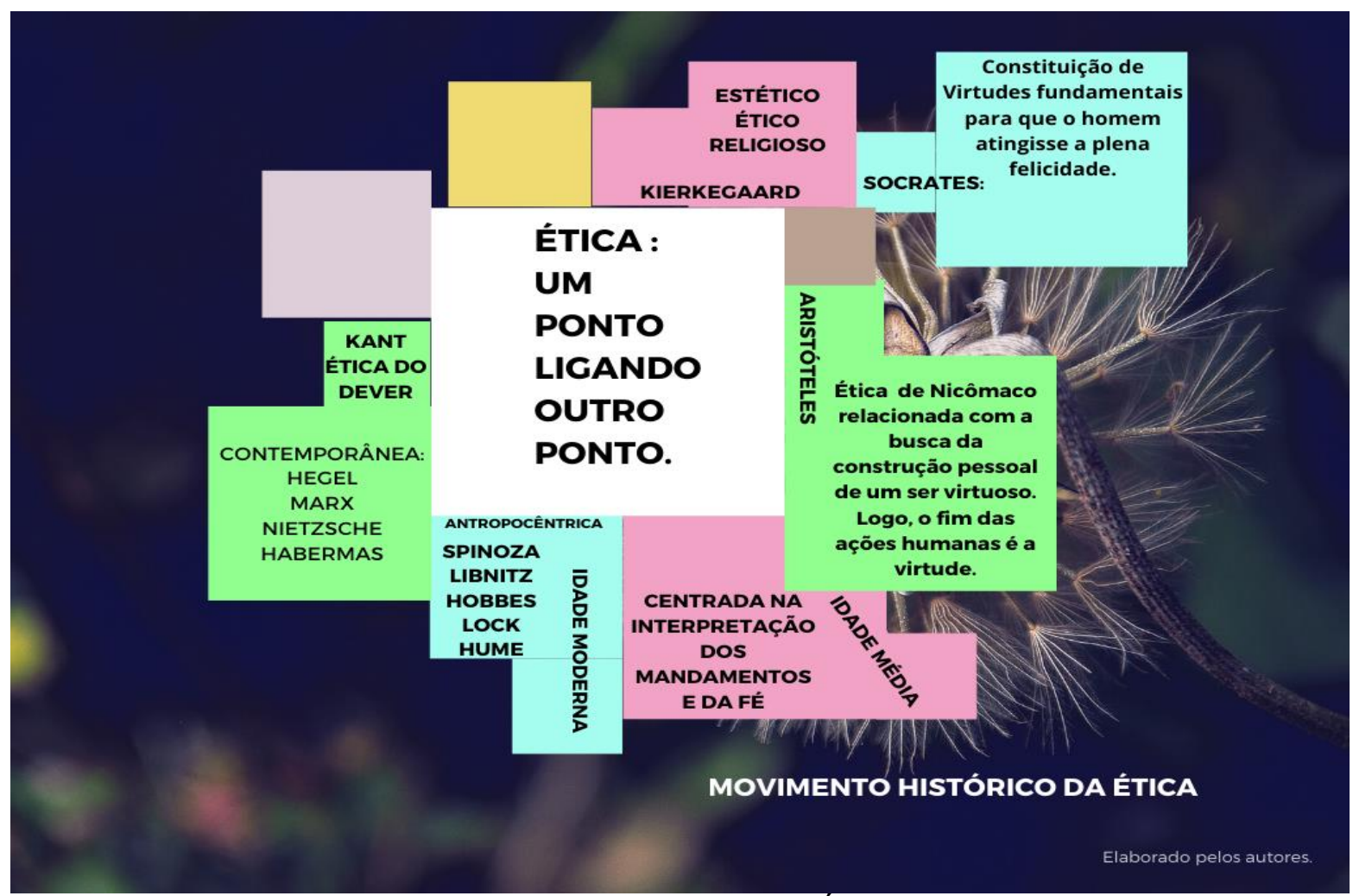

Figura 1: Breve História da Ética.

Fonte: elaborado pelos autores.

Enquanto ciência a ética surge com os gregos (CHAUÍ, 2015) na figura e filosofia de Sócrates condenado por transgredir normas e imposições éticas absolutistas, valoriza um princípio ético básico de que ninguém pode lesar ninguém. Para o filósofo se uma pessoa permanece num lugar do qual poderia sair, este tem por dever obedecer às leis e normas deste lugar. Já Platão centra suas indagações na ideia perfeita, justa que organiza a ação e a conduta humana; A ética em Platão é entendida a partir do uso da razão, visto que, para o filosofo a ética faz parte do humano, sendo ela também o meio de alcançar os valores a serem seguidos por todos. Para Aristóteles a ética se inicia pela ideia de felicidade que é o bem e o fim para encontrar a felicidade, logo, sem o bem não há como chegar a felicidade que só pode ser atingida com o outro. Essa ética grega surge tendo como referência o princípio da regra de ouro de que "não faça aos outros aquilo que não gostaria que fizessem a você".

Na Idade Média (BORNHEIM, 2009) a elaboração ética em grande parte da Europa assume a roupagem do catolicismo cujo ordenamento e modo de ser e estar no mundo seguem o horizonte da fé que orienta a razão. Ela trata das grandes questões existenciais do ser e do destino. Também possui uma orientação clara a ser seguida no atingimento de fins metafísicos propostos pela perspectiva teológica dessa época. O agir humano deve estar em 
consonância com a vontade divina. $O$ homem que deve se reconhecer como criatura de um criador ordenador do universo. A grande mudança que com a modernidade está associada ao papel que o humano começa a assumir nesse contexto. A perspectiva moderna antropocêntrica inaugura uma nova metafísica conforme (HERMANN, 1999), a metafísica da subjetividade. Desse modo Descarte, Bacon, Rousseau, Kant, Marx, Comte entre outros se esforçam em demonstrar como o sujeito é a nova categoria moderna capaz de reunir em si todas as condições de assumir e atribuir sentido ao universo. Por isso a modernidade é marcada pelas referências a esse sujeito em prospectar grandes narrativas visando atingir teleologias coletiva para a humanidade.

No próprio bojo da modernidade surgiram inúmeros questionamentos sobre os caminhos que a humanidade estava tomando principalmente pela forma como a racionalidade e a perspectiva positivista estava operando nas relações de domínio da natureza pelo sistema capitalista. Ou seja, tanto Rousseau quanto Marx já apontavam que os projetos modernos apresentavam patologias que estavam fazendo com que a humanidade tomasse o bonde errado da história.

As críticas a esse modo de pensar e proceder denunciam que a racionalidade estratégica e metafísica voltada a fins, cujo endereçamento é o aumento do lucro e do poder possuía em si inúmeras patologias. É o que os pensadores da Escola de Frankfurt que identificam a gênese desses desvios da humanidade que culminam nas relações de domínio da natureza presentes nas narrativas da mitologia grega. A obra Dialética do Esclarecimento demonstra os contornos da gênese do capitalismo presentes na mitologia a partir da narrativa de Ulisses o grande conquistador que nega as emoções para atingir suas conquistas. As insuficiências desse paradigma atualmente podem ser constatadas na grande crise socioecológica onde ficam explícitas as limitações do modo de produção capitalista na preservação e garantia da vida. Trata-se de uma crise com dimensões imensuráveis.

\section{Dilemas Éticos postos pelo COVID-19 e a reivindicação de uma Ética Ambiental}

Diante do cenário mundial que se desenha a nossa frente, como uma pintura repleta de nuances de arte e tragédia, de perda de referencial, isolamento social, que caminhos éticos podemos encontrar que apontem para algumas possibilidades de responder aos dilemas éticos que vivemos na América Latina e Caribe? Que horizontes éticos podemos vislumbrar para tornar possível uma ética que nos possibilite repensar o nosso modo de ser e de agir que nos trouxe até aqui? Em relação a América Latina e Caribe tão explorada quais as possibilidades éticas para nossa região?

Em meados de 1970, um grupo de estudiosos convencionou, segundo o dicionário da filosofia (2015, p. 450) que 'a ética somente tem sentido nos limites em que seja relevante para a vida em sua pratica', compreendemos 
então que uma ética em nosso tempo é a que se propõe ao cuidado, ao afeto, ao retorno de um sentimento profundo de ligação com GAIA, enquanto organismo vivo, é, portanto, uma ética de cuidado. Uma ética Ambiental entendida aqui como uma escolha por um modo de ser e estar no mundo considerando que somos todos um. Mas como podemos chegar a esse modo de ser? Se do humano emerge a tragédia da degradação da vida, pode também desse mesmo humano vir uma outra maneira de vida? Segundo BOFF (2011, p.10) 'viver humanamente', isso significa ativar em cada um de nós princípios de vida que nos orientem a ética do cuidado (BOFF, 2011), a solidariedade universal $(B O F F, 2011)$ que nos orienta na direção do resgate da capacidade de colocar-se com empatia no lugar do outro.

Nossos dias estão por certo diferente neste histórico ano de 2020 em múltiplos sentidos. A presença nefasta da COVID-19 devastando vidas em todos os lugares do mundo acende um alerta importante: os dilemas éticos da nossa forma civilizatória, exploratória e capitalista de habitar esse lugar, nossa Casa. São dilemas que sempre estiveram aí, mas preferíamos não os ver. Apresentamos dentre tantos dilemas 4 que consideramos emergentes nesse momento como acontecimentos que estão diante de nós.

1. Dilema do cuidado com a vida em todas as suas manifestações: entendemos que esse dilema aponta para necessidade de nos dedicarmos a pensar como se fez toda cadeia de vítimas, não somente da Pandemia, mas vítimas da desigualdade social extrema, da riqueza que se acumula nas mãos de poucos em detrimento a miséria de muitos. Vítimas de políticas públicas desiguais, de sistemas de saúde deficitários, de desgovernos que colocam em risco toda vida de um povo, de uma devastação ambiental sem precedentes. Desse dilema o que esperamos na Pós-pandemia, é o nascimento de uma sociedade de colaboração, visto que, nasce aí na pandemia a semente da certeza de que precisamos repensar nossa relação com o ter e o ser. A sociedade da colaboração nasce na Pandemia como uma rede que não é de bondade, mas de necessidade, porque o dinheiro, que até então parecia dar uma certeza de segurança, diante do vírus, já não interessa, porque o cuidado passa pela permanência em casa e não na produção, no consumo e no acumulo frenético que nos movia. É evidente que no póspandemia teremos múltiplos conflitos para ressignificarmos o mundo a partir de uma perspectiva ética baseada na solidariedade e no trabalho coletivo que se posicione a favor de outra forma de cuidado e manutenção da vida.

2. Dilema ético do luto: Como poderemos pensar a ética a partir do cenário de luto? São mais de 300.000 mortes vítimas da Pandemia em todo mundo. Olhar as fotos, saber os nomes, os amores, as vidas dos que o vírus nos tirou deixam evidentes que é a vida que importa, é de vida que falamos. O luto é planetário, mas o que estamos vivendo nos 
traz a memória que as escolhas que estamos fazendo por um longo tempo nos trouxe até aqui, e portanto, esse dilema do luto, da impossibilidade do rito de despedida, sinaliza também uma orientação a repensarmos eticamente o que estamos fazendo pelos que virão. Talvez nossa geração não veja o que fizemos aqui, temos que sobreviver para testemunhar que no Pós-pandemia outro modo de viver precisa nascer. Um convite a reposicionar a vida. Carregar a memória dos que sucumbiram ao vírus é um dilema ético de projetar um hoje melhor.

3. Dilema das múltiplas desigualdades: Esse é um dilema que se subdivide em outros tantos, mas que apenas apontaremos para que outros possam ampliar conosco. Escolhemos olhar para nossa casa o Brasil e demais países da América Latina e Caribe, onde convivemos com uma desigualdade socioeconômica gigantesca. Temos um sistema inteligente de saúde, mas sucateado pela corrupção. Temos um desgoverno que em plena Pandemia age de maneira absurdamente sem ética, respeito as recomendações da Organização Mundial da Saúde, que participa e incentiva manifestações absurdas que atentam a democracia. Desigualdade Educacional, nos últimos 30 anos tivemos mais acesso à educação, mas vivemos numa educação que não se movimenta, não permite ousadias, autonomias, o que dificulta imensamente a compreensão de uma ética de luta por igualdade e respeito as diversidades.

4. Dilema da tradição: São grandes questões que nos orientam a reposicionar diante do mundo da vida, enquanto humanidade. Conectarse com questões essenciais: o que é justiça? Ética, política, a legitimidade da política, apontar para o que ainda não está pronto, olhando para o que os movimentos que nos trouxeram até aqui, colocar a ética como pano de fundo de outro mundo, concordamos com Boff (2020) que o Pós coronavírus será um freio necessário ao modo insustentável de vida, 'depois do coronavírus não é mais possível levar avante o projeto do capitalismo como modo de produção nem do neoliberalismo como sua expressão política'. O retorno a ideia de coletividade e comunidade poderá significar um bom recomeço, mas há também de pensarmos além. Não será mais possível que toda riqueza mundial se concentre entorno de poucos, afinal, continua Boff (2020), 'o capitalismo é somente bom para os ricos; para os demais é um purgatório ou um inferno e para a natureza, uma guerra sem tréguas. $O$ que nos está salvando não é a concorrência (seu motor principal), mas a cooperação, nem o individualismo (sua expressão cultural), mas a interdependência de todos com todos'. Essa relação com a tradição, sob olhar da Ética Ambiental é um convite a superação deste momento vivido com sabedoria e coletividade, vencendo egoísmos, vaidades e 
pensando na totalidade, na intrínseca relação de irmandade que originalmente nos une, como canta lindamente Anavitoria (2020): "Daqui, eu vi o tempo parar. Pra gente se lembrar da força que é alguém do lado. Pra gente entender que nós e o chão somos a mesma coisa".

Um momento como este no impele a perspectiva da generosidade como uma autoproteção. Mas, o vírus não será apenas uma evidência de uma crise já existente? Questões como essa reivindicam a Ética Ambiental. Desse modo, pensando em Ética Ambiental faz-se necessário traçarmos o movimento que tangencia o surgimento desta preocupação com os rumos de nossas escolhas e do quão perigoso esse caminho obscuro é. O Antropoceno; do grego 'antropo' significa humano e 'ceno' denota as eras geológicas, já destacado, estudo e proposto por Paul Crutzen (2006) é portanto a época dos humanos, a época do homo sapiens, a época em que constatamos que a civilização humana se expande, somos bilhões de pessoas no mundo e seguimos nos multiplicando. Mas é também nessa época humana que encontramos uma apropriação consumo avassalador da natureza, dizemos consumo, pois é a palavra que com mais exatidão define essa pretensa posse, essa exploração insana que fazemos da Terra de onde retiramos e nada devolvemos. Somos uma civilização nociva à Terra, sim, nós os humanos, somos os responsáveis pela degradação da vida na Terra. É uma afirmação dura, mas real, tristemente real. É nossa responsabilidade a situação da vida ameaçada, sofrida, sumida de milhares de espécies diariamente. Poderíamos dizer que aqui neste contexto humano temos a vigência de uma ética antropocêntrica (GRUN,2010) esta ética qualifica o humano como construtor do mundo, e reina absoluto. Esta ética está ligada a consolidação de um domínio da técnica, do capital, os princípios desta ética são centrados no ter, na construção de máquinas, assistimos a expansão da exploração dos recursos naturais como pose.

Para dar conta deste projeto moderno de domínio afastamos a sensibilidade, o cuidado pela vida, a capacidade de colocar-se no lugar do outro.

Os padrões dominantes de produção e consumo estão causando devastação ambiental, esgotamento dos recursos e uma massiva extinção de espécies. Comunidades estão sendo arruinadas. Os benefícios do desenvolvimento não estão sendo divididos equitativamente e a diferença entre ricos e pobres está aumentando. A injustiça, a pobreza, a ignorância e os conflitos violentos têm aumentado e são causas de grande sofrimento. O crescimento sem precedentes da população humana tem sobrecarregado os sistemas ecológico e social. (CARTA DA TERRA,1987, p 01).

Quando perdemos de vista nosso horizonte de partida que nos identificava como pertencentes a mesma Casa-de-vida (SAUVE,2005) nesse momento se 
dilui nossa capacidade de perceber que o crescimento da ganancia, do capitalismo excludente e a cegueira que impede de ver o sofrimento do outro, e, caminhamos a passos largos para o fim. Uma sociedade sem ética, uma sociedade de fake News chama seu povo para a sepultura. Uma ética Ambiental nos conclama para união. Acreditamos que este momento de Pandemia pode ser de grande oportunidade para reforçarmos o cuidado, porque estamos unidos pelo sofrimento. Estamos a séculos explorando nossa Casa Gaia e ela nos suportando, até que ao chegar no extremo começa a dar sinais de que não é mais possível suportar e manda o aquecimento global, os eventos extremos, vários vírus, e agora o Coronavírus, chamando-nos a compreensão de que como organismos vivo nossa Mãe sente, sofre, mas também se mantem. Logo, é preciso acordarmos do sono profundo de sermos superiores e compreendermos que poderemos ser uma das espécies extintas da Terra.

Este é um momento de paciência e ciência, mas não somente, é também uma convocação para estabelecermos outra relação com nossa mãe. Uma relação de cuidado amoroso e respeitoso da vida em todas as suas múltiplas manifestações. Uma Comunidade Planetária Pós Pandemia não pode ser o que era antes, isso seria uma terrível ausência de evolução. Nesse sentido acreditamos que não há como mantermos esse mesmo capitalismo feroz e nocivo a vida.

\section{O contexto da Crise Socioecológica na América Latina e Caribe e a reivindicação da Ética Ambiental pós COVID-19}

Sabemos que nossa Latina e Caribe há muito tempo vive uma crise com proporções imensuráveis. Trata-se em de uma crise mais ampla associada aos grandes problemas mundiais que demarcam através do sistema capitalista a existência de inúmeras patologias socioambientais. Analisar alguns aspectos dessa crise no contexto da pandemia do COVID-19 tem por objetivo reforçar nossa identidade e modo de ser, além de buscar ampliar nossa solidariedade com os nossos vizinhos. O que percebemos é que a mídia oficial em relação ao COVID-19 teve como foco a divulgação das informações da Ásia, Europa, Estados Unidos e Brasil. Sentimos dificuldades de perceber como esses movimentos estão ocorrendo na América Latina e Caribe como um todo. No entanto, ainda que tenhamos problemas e identidade comuns no que concerne ao COVID-19 cada país da América Latina e Caribe vivencia as demandas ao seu modo de acordo com as condições que se tem para o enfrentamento.

Sabemos que nossa região enfrenta grandes problemáticas de um mundo pré-COVID-19 na luta por justiça ambiental. Em estudo anterior (PEREIRA, 2020) destacamos alguns dos problemas que fazem com que na América Latina haja maior vulnerabilidade frente ao COVID-19 de que em outros contextos com maior organização política, mesmo que o Vírus tenha mostrado que nenhuma nação é inatingível. Dentre as principais dificuldades destacamos em nossa região: a) o modelo de desenvolvimento econômico 
voltados para o uso e abuso da extração de recursos naturais; (destacamos os grandes impactos pela vida através da mineração desenfreada na maioria das nações e pelo impacto criado pelo uso da matriz energética do carvão e do petróleo). Demonstramos que em nossa região o capitalismo é mais agressivo que outros contextos pela forma de exploração dos recursos naturais e humanos. (com destaque para violência contra campesinos, indígenas, negros e negras LGBTs e mulheres de diferentes campos de ação); b) a fragilidade democrática faz com que muitos países na américa latina estejam nesse momento em contextos de democracia em afirmação ou em risco. Associa se a isso o retorno de governos populistas de extrema direita, como é o caso do governo Bolsonaro no Brasil e o desrespeito pela vida em suas ações. c) $O$ continente antes do COVID-19 já apresentava alto índice de desemprego; d) como consequência do desemprego, da corrupção e do narcotráfico, o aumento da pobreza extrema é outro grave problema. e) outra decorrência de problemas socioambientais e econômicos, as migrações ambientais consistem num outro fator que mobilizam milhares de humanos na América Latina e Caribe em busca de garantia de vida. f) A grande concentração de renda nas mãos de poucos e a consequente falta de maior redistribuição de renda na mão de muitos excluídos. g) as dívidas externas, a dependência dos países desenvolvidos em especial da China e dos Estados Unidos além dos altos tributos também são fatores de baixa expectativa de crescimento numa américa latina e Caribe pré-COVID-19.

Consideramos que a chegada do COVID-19 em nossa região em nada esconde esses problemas, ao contrário os amplia significativamente. É nessa perspectiva que consideramos que nos países latino-americanos a vida está sendo mais ameaçada ainda em relação a outras nações com maior desenvolvimento.

Conforme os dados do observatório Covid-19 da Comissão Econômica para América Latina e Caribe - CEPAL, somos na América Latina e Caribe uma população de 650 milhões de habitantes. Essa população historicamente vem passando por inúmeras dificuldades já mencionadas. O agravamento dessa conjuntura pelo COVID-19 muda drasticamente a nossa região que já se aproxima das 30 mil mortes sendo que o Brasil assume o quarto lugar do mundo em número de mortos já superando as 16 mil mortes com média 62,3 mortes por milhão de habitantes. A situação ainda mais preocupante é a do Equador cuja média é a de 132,3 mortes por milhão de habitantes e o Peru 65,8. A expectativa do México é que superará as 6 mil mortes. Dados gerais apontam que na data de 18/05/2020 o número de casos na América Latina já ultrapassa meio milhão de seres humanos infectados de um total mundial de 4.565.96.

Em meio ao desespero e grande dilema ético de salvar o maior número de vidas possíveis as ações dos governantes estão sendo no sentido de fechamento de fronteiras, cancelamentos de vôos, isolamento social, transferência diretas de recursos para os mais pobres e microempresas, melhorias urgentes no sistema de saúde, contratação de pessoal especializado

revista brasileira educação ambiental 
em saúde, e adoção da quarentena com muitos decretos, além de campanhas de conscientização.

Dados da CEPAL (2020) para uma América Latina e Caribe pós COVID19 indicam um aumento de mais de 12 milhões de desempregados em nosso continente que possui uma população de 650 milhões de habitantes. Outro preocupante dado é sobre o aumento de mais de 30 milhões de pessoas em situação de pobreza. Em 2019 o continente já possuía 191 milhões de pobres sendo que 63 milhões em situação de pobreza extrema. Estaremos chegando a 221 milhões de pobres na América Latina e Caribe. Além disso, vivemos a pressão da economia que aponta para uma violenta quedo no PIB de $5,3 \%$ em nossa região.

No esforço propositivo pelo horizonte dos Fundamentos da Educação Ambiental passamos apresentar a partir de agora alguns princípios que possam contribuir para pensarmos uma Ética Ambiental para América Latina e Caribe pós COVID-19. Reconhecendo tratar de uma tarefa de difícil alcance em linhas gerais ela passa por possibilidades e escolhas que poderemos fazer no sentido de podermos garantir vida digna em nossa América Latina e Caribe.

\section{Ecossocialismo e a ruptura com o modelo de desenvolvimento capitalista}

Destacamos nesse estudo de que um dos maiores problemas causador de inúmeras injustiças e patologias socioambientais no nosso continente, consiste no modo de produção capitalista com seu modelo de desenvolvimento. Consideramos ser um sistema de descuido com a vida. Basta ver o grande número de humanos excluídos que não contam em sua contabilidade. Além disso a forma que estabelece as relações humanidade-natureza tem demonstrado grande exploração a partir de uma perspectiva antropocêntrica e predatória que utiliza os recursos máximos em favor do lucro, concentração de riqueza e do poder. Ao considerarmos o Ecossocialismo como um horizonte ético possível, o que se propõe é uma ética que deve partir de uma perspectiva anti-sistêmica. $\mathrm{E}$, consequentemente em defesa da vida realizar não apenas uma inversão axiológica, mas uma ruptura com esse modo de produção. Nessa perspectiva temos a seguinte escolha a ser feita:

a) a propriedade coletiva dos meios de produção (o termo "coletivo" aqui significa propriedade pública, comunitária ou cooperativa), b) um planejamento democrático que possa permitir à sociedade a possibilidade de definir seus objetivos no que concerne ao investimento e à produção e c) uma nova estrutura tecnológica das forças produtivas. Colocando de outra forma, uma transformação revolucionária em nível social e econômico (LÖWY, 2020, IHU). 
Entendemos que o Ecossocialismo coloca a perspectiva da vida em outro patamar onde a vida é assumida como coletiva. Condição tão necessária para nossos projetos na busca de superarmos a lógica neoliberal, onde a individualidade é condição fundamental para a competitividade. Também acreditamos que uma ética ecossocialista apresenta não apenas uma mudança de princípios, mas a reivindicação de novos modos de ser que passa pela redefinição do modo de produção, de convivência, de participação e de estabelecimentos de outras teleologias cujas finalidades garantem melhor a vida coletivamente. É claro que essa mudança não se trata de um salto, mas de processos de conscientização profundas e níveis de participação que reivindicam horizontes planetários, mais justos em defesa da vida digna. Acreditamos que uma sociedade pós COVID-19 deva pautar suas escolhas coletivas, romper com velha economia e investir em novos modos de conviver, gerir, defender e planejar o futuro coletivamente. Isso passa por ações, e, fundamentalmente por escolhas. Consideramos que o COVID-19 criou condições de percebermos que desde o Uruguai até o México existem movimentos em toda a América Latina que contestam o sistema capitalista e reivindicam outros modos de ser e de conviver mais cooperativos e solidários. Devemos reforçar mais as redes que já existem e criarmos outras tantas redes éticas e ambientais que reforcem experiências originárias na defesa coletiva da vida em toda a América Latina e Caribe.

\section{O reconhecimento e a valorização da Pachamama}

Igualmente importante, nesse momento de COVID-19 consideramos como dimensão ética para América Latina e Caribe todo um conjunto de saberes que já possuímos de modo organizado oriundos da Pachamama, ou de la Madre Tierra. Esse horizonte ético aponta para novas maneiras de nos relacionarmos com a natureza. Dela emerge as potências criativas da vida e do feminino. A Pachamama como horizonte ético ambiental, valoriza a diversidade e ressignifica a vida digna. Nesse sentido, com grande destaque na Bolívia e no Equador a perspectiva ética da Pachamama serve de horizonte não apenas para o avanço no marco constitucionalista latino-americano, mas como referência nos modos de ser e de conviver que apontam para uma ressignificação ontológica na clássica relação humanidade-natureza. Amplia nosso horizonte na direção do reconhecimento de da natureza que rompem e superam a relação de sujeito-objeto gestada na modernidade europeia. Ao contrário ao considerar os direitos de la madre tierra o que temos como horizonte possível é uma relação ética intersubjetiva, não hierárquica, que supera a relação de domínio.

Sem dúvida essa perspectiva enquanto modo de ser numa sociedade pós COVID-19, alteraria profundamente as relações. Assim ampliaríamos ainda mais nosso pertencimento, a valorização aos povos tradicionais, e manteríamos relações de maior cuidado ambiental. Com isso teríamos maior respeito ao ambiente em que se vive, fulcrada na experiência vivenciada pela 
valorização do feminino da diversidade dos povos que compõe a América Latina e Caribe.

\section{Reconhecimento e defesa dos povos marginalizados}

Uma perspectiva ética para a América Latina e Caribe pós COVID-19 deve partir do reconhecimento dos mais excluídos em nossa região. Já apontamos anteriormente sobre o quadro de agravamento de diversas populações e do aumento significativo de pobres no continente. Igualmente vivenciamos alguns movimentos éticos na busca de perspectivas solidárias. Elas são diferentes com interesses diferentes. Vão desde ações de Governos, Sistema Financeiro e Grupos de Empresários com o discurso de renovação e retomada da economia urgente.

Além disso, temos inúmeros movimentos que vão das periferias aos grandes centros como formas de organização e lutas em defesa da vida. No Brasil se destacou o caso de inúmeras instituições vinculadas a pauta dos direitos humanos que assinaram um documento e cobram dos governantes políticas que considerem prioritariamente os mais excluídos e os mais vulneráveis: moradores de ruas, domésticas, LGBTs, desempregados, povos tradicionais indígenas, africanos, negros e negras, pequenos produtores, campesinos, mulheres campesinas, vendedores informais, população de serviço autônomo e informal dentre tantos outros. Nesse momento estamos com ameaça real de extinção de 700 povos indígenas por não possuírem recurso sanitário e de saúde em suas aldeias que de conta do enfrentamento do COVID-19. Essa ameaça passa também pelas comunidades campesinas e quilombolas com difícil acesso ao sistema de saúde.

Acreditamos ser o momento em que a Ética Ambiental possa servir para reafirmarmos da perspectiva de horizonte solidário latino-americano e caribenho. Isso passa por conhecermos os problemas que nossas nações vizinhas estão passando, posteriormente buscarmos parcerias e definirmos estratégias e pautas comuns. A solidariedade latino-americana reivindica 0 reconhecimento da alteridade, a aproximação de objetivos comuns e a opção política em favor dos mais vulneráveis. Necessitamos de um projeto comum que não seja ditado pelos órgãos financeiros como ocorre atualmente uma espécie de ditadura do PIB. Passa também pela crítica a grande concentração de riqueza que o sistema implementou em nossa região. O COVID-19 nos ensina que a dor da perda de um ente querido quer seja no Uruguai, Brasil, México, Peru ou Equador é a mesma e precisamos tratá-la como um problema nosso. Se quisermos enfrentar os problemas que de fato afetam nossa América Latina e Caribe e diminuirmos os níveis de exclusão devemos buscar solidariamente reforçar nossa identidade comum e rompermos com esse sistema de descuido a vida que ora impera. 


\section{Mudança da matriz energética}

Acreditamos que a oportunidade que estamos tendo, mesmo com ônus muito alto o COVID-19 decreta sem dúvida a falência da matriz enérgica do petróleo. Posição diferente a grandes especialistas (LOWY, 2020); (SATO; 2020) que acreditam que não haverá mudanças. Consideram que na verdade tudo o que os imperadores da matriz do Petróleo e do carvão querem é a retomada imediata do seu modus operandi. Consideramos ser essa matriz causadora de danos ambientais desde a extração, transporte, até vazamentos de inúmeras proporções. É também causadora de grandes índices de poluição. Essa matriz está associada a grande concentração de riqueza e de poder em nossa América Latina e Caribe. Dentre os 50 países com maiores reservas de petróleo do mundo estão os seguintes países latino-americanos: Venezuela ( 1 은

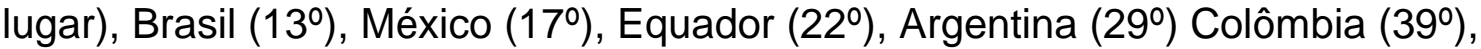

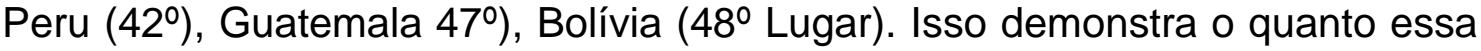
matriz está internalizada em nossa vida. Também aponta para o interesse colonialista nos acordos por controle das referidas reservas.

Vemos uma sociedade latino-americana e Caribe Pós COVID-19 com maior resistência a referida matriz energética e com maior abertura para adoção de energias mais limpas. O COVID-19 pode servir para acelerar a adoção das energias renováveis em escala mundial, através da eletrificação dos transportes e dos sistemas de aquecimento, além da utilização mais direta das fontes limpas. Os objetivos da Agência Internacional de Energia Renovável para 2050 poderão ser atingidos bem antes caso tenhamos a coragem de fazer essa escolha. Creio sem dúvida que essa escolha passa pela conscientização da população e por decisões políticas em grande escala em nosso continente. Nesse sentido a Educação Ambiental pode também contribuir nesse processo educativo.

\section{Ontologia da Esperança como horizonte de resistir para existir}

A perspectiva maior da Ontologia da Esperança trata-se de uma obra coletiva organizada com a Professora Marcia Malta. Nesta obra diferentes autores do campo da Educação Ambiental do Brasil apresentaram seus espaços de lutas no campo popular ambiental e a possíveis alternativas para a Educação Ambiental em Tempos de Crise e todos os problemas que assolam o Brasil e a América Latina. Nesse esforço de pensar uma Ética para América Latina resgatamos alguns argumentos do capitulo primeiro onde procuramos justificar a necessidade frente a todas as situações de violência que estamos vivendo, ainda na sociedade pré-COVID-19 e a agora, mediante a pandemia, mais ainda como a capacidade de resistir para existir no sentido ontológico do esperançar freirano enquanto dimensão de luta.

Considerando as contingências de um presente que ainda não anuncia um porvir de esperanças percebemos a necessidade de que o existir no tempo presente é precedido pelo verbo resistir. Nesse sentido, a condição ontológica 
da resistência traz consigo a força e a necessidade do existir. Resistimos aos sentimentos de vingança, ódio e fobia tão presentes nas novas expressões dos movimentos fundamentalistas brasileiros e latino americanos antidialógicos. Suas armas são imperativos contra toda e qualquer diferença. Essa perspectiva é tão forte que chegam até reivindicar as forças armadas para assumirem o comando do Brasil, por exemplo. Suas estratégias transcendem a dimensão religiosa e chega a e ter alcance direto na vida pública da população. A resistência como condição ontológica refere-se também a necessidade de resistirmos "ao canto da seria" do discurso neoliberal que muda a legislação em Educação Ambiental em favor de um falso "desenvolvimento sustentável" a serviço da lógica do mercado. A resistência também diz respeito a morte de mais de 32 mil pessoas no campo conforme levantamento da Pastoral da terra sendo apenas nesse ano mais de 70 até o mês de abril de 2019 (verdadeiros genocídios e chacinas). Essa ontologia serve para resistirmos a desvalorização do ensino público em vista dos novos investimentos no setor privado.

Considerando que todas essas violências encolhem a nossa condição de "ser mais" no sentido freiriano e não querendo ser mais um ser biológico adaptável aos golpes políticos, a exploração humana em todas as dimensões, a exploração da natureza e aos descuidos desmedidos respaldados em legislações a serviço do capital, a ontologia está associada a nossa possibilidade de transcendência aos limites impostos pelo sistema. Transcendência aos fatalismos impostos de que não podemos mais ter acesso a isso ou aquilo. Essa ontologia da esperança refere-se a uma condição de movimento, abertura compreensiva e existencial, de percepção da nossa busca de infinito mesmo sendo finitos. Trata-se de uma ontologia que não coloca a esperança no topo num alcance metafísico ou numa teleologia, mas, vê o esperançar como condição existencial de um humano que por ser humano pode escolher viver reflexivamente do que se adaptar biologicamente. Assim somos criadores de nossa própria cultura, mas também transformadores de nossa existência. Esse movimento ético existencial propiciado pela ontologia da esperança só pode ser compreendido nas relações com todas as outridades: humanas e não humanas. Nesse sentido os retrocessos democráticos no Brasil e na América Latina buscam nos impor um modo de viver inautêntico. Finalmente a Ontologia da Esperança nos permite no contexto do COVID-19 enquanto dimensão ético-política, que retomemos o sentido mais amplo de nossa existência a tudo que a circunda e a partir disso nos projetemos ontologicamente como possibilidade reconfiguração existencial coletivamente.

\section{Defesa da vida e dos recursos naturais}

É sabido desde há muito a quanto perversa é a lógica capitalista no uso dos recursos naturais. Ela vai desde práticas de práticas de desmatamento, extração e de mineração, produção em grande escala do agronegócio, instalação de usinas hidrelétricas e o grande abuso na questão dos recursos 
hídricos. São hidronegócios a favor de interesses políticos e financeiros em toda a Amazônia como demonstram (BATISTA; MIRANDA, 2019). Uma ética ambiental para uma a América pós COVID-19 passa pelo enfrentamento das grandes questões que estão cotidianamente a serviço do mercado. Sabemos que temos problemas de água em quase todo o continente e corremos risco não pela sua ausência, mas pela forma de exploração. Em pleno contexto de COVID-19 a organização Wildlife Conservation Socyte denuncia a captura e a comercialização ilegal de diversas espécies de animais silvestres no Peru; problemas de escassez de água no Chile decorrente dos processos de mineração, igualmente no México onde de norte a sul ocorrem descargas de aguas residuais sem permissão em mais de 5 mil poços por parte de empresas de bebidas, alimentos, higiene, construção, mineração, têxtil e outros setores. Nessa mesma lógica há o aumento das atividades de mineração no Uruguai com o falso discurso de reativar a economia. No Brasil em meio a pandemia há uma aceleração do desmatamento na Amazônia e a proximidade do início da época dos incêndios florestais, com o acirramento dos conflitos envolvendo invasões de terra e a intensificação da violência contra os agentes dos órgãos ambientais. Além disso grande manifestação de organizações contra a aprovação da Medida Provisória (MP 910) denominada pelos grupos de resistência como a MP da grilagem.

O que se nota é ainda a perspectiva antropocêntrica numa relação humanidade-natureza similar a relação sujeito-objeto. Uma ética ambiental para nossa região não deve se eximir de contestar essa forma de prejuízo a vida em nome da economia de mercado causadora de muitos danos colaterais as populações tradicionais vizinhas. Acreditamos que o COVID-19 cria condições para pensarmos além de novas formas de consumo, nos provoca a pensarmos na agricultura ecológica como horizonte a ser seguido na América Latina. Temos boas práticas nesse sentido em todo o continente.

\section{O enfrentamento das mudanças climáticas como resultado da ampla crise civilizatória}

A pauta das mudanças climáticas não pode ser vista desconectada da maioria das reivindicações já aqui colocadas. Na América Latina segundo a CEPAL, Costa Rica e Uruguai ostentam dos dois melhores índices de sustentabilidade. Outrossim, os estudos apontam que em todas as legislações Ambientais dos países da América Latina e Caribe estão presente a pauta do desenvolvimento sustentável e do enfrentamento das mudanças climáticas. Por todos os motivos até aqui expostos dado a economia capitalista e as patologias socioambientais criadas pensamos que o COVID-19 mostrando a grande vulnerabilidade que o planeta vive sem deixar ninguém imune, reforça o nossa responsabilidade e compromisso com ruptura com esse modelo e com o desenvolvimento urgente de trabalharmos cotidianamente a temática das mudanças climáticas. Em nosso entender o COVID-19 escancara os motivos de uma crise maior e demonstra os sinais mais evidentes da vida que se torna

revista brasileira educação ambiental 
ameaçada e ceifada a cada dia. Não há mais tempo para protelarmos a ruptura com a velha economia e o avanço no sentido da defesa da vida a partir do enfrentamento dos conflitos que mudam o curso de perspectivas em favor da vida. o COVID-19 nos mostrou que as mudanças climáticas são sintomas de patologias socioambientais de um mundo que adoeceu. Dessa forma, uma Ética Ambiental para nosso continente e planeta deve considerar esse grave quadro e orientar ações no sentido de evitarmos futuras pandemias e mitigarmos muitas patologias socioambientais. Acreditamos que a Educação Ambiental assume um papel fundamental nesse processo, principalmente com o aspecto formativo conscientizador sobre o nosso compromisso individual e coletivo.

\section{A perspectiva ética da Ecologia Cosmocena enquanto horizonte de cuidado}

Consideramos que o horizonte da Ecologia Cosmocena apresenta inúmeras reivindicações éticas que podem contribuir nesse pensar uma Ética Ambiental para América Latina pós COVID-19. A partir de uma perspectiva hermenêutica existencialista a Ecologia Cosmocena reivindica: uma nova relação natureza-humanidade, a desaceleração do tempo como garantia da vida, da sintonia com as velhas e novas sabedorias, do cuidado como reaprendizagem versus o consumo desenfreado, da descolonização do mundo da vida, do reconhecimento de um mundo diverso sem preconceitos, da nossa condição de incompletude e do lugar da Educação Ambiental na perspectiva do ambiente inteiro.

Defendemos amplamente em diferentes momentos de que a Ecologia Cosmocena se trata de uma perspectiva ontológica sobre a necessidade do reposicionamento do ser humano no cosmos. Acreditamos que o contexto do COVID-19 cria condições para retomarmos as questões de sentido postas pela referida ecologia. Nesse sentido, no limite em que perdemos milhares de vida no mundo e na América Latina e Caribe convém revistarmos enquanto horizonte ético a Ecologia Cosmocena no sentido de pensarmos uma Ética Cosmocena. Ela nasce como alternativa ao antropoceno e a todas as formas de descuido denunciadas nesse trabalho. É uma ética em favor do cuidado, do reconhecimento, do respeito a todas as outridades que integram o universo. Uma ética preocupada com as relações que estabelecemos com os que estão longe, mas fundamentalmente com os que estão perto. Uma ética que reivindica inclusive o cuidado com espiritualidade no sentido contribuir com 0 a avaliação e com o reposicionamento do humano no universo. Trata-se de uma ética em que o pano de fundo é a existência e a reflexão sobre ela consiste numa tarefa primeira. Essa ética critica profundamente o capitalismo como sistema de descuido e se coloca na defesa e reconhecimento de todas as diferenças e na supressão de todo e qualquer preconceito. Consiste numa ética de reconhecimento e de valorização dos saberes e das ontoepismelogias ancestrais dos povos tradicionais, indígenas, africanos, quilombolas, povos das 
floretas, campesinos, negros e negras, mulheres campesinas. Portanto é uma ética contrária a toda e qualquer tentativa de colonização de saberes e doutrinação eurocêntrica. É uma ética antissistema contrária todas as formas de exclusão: uma ética a favor dos excluídos.

Acreditamos que uma Ética de horizonte cosmoceno pode sim contribuir com alternativas verdadeiramente sustentáveis em defesa não apenas de qualquer vida, mas de vida digna. $\mathrm{E}$ essa vida que reivindicamos ao nosso continente tão sofrido, mas com tamanha capacidade de resistência. É por esse viés que podemos estar escolhendo por modos de ser e conviver em nossa américa latina e caribe que potencializem a vida. As informações estão dadas cabe agora a consciência e a responsabilidade de escolha que faremos.

\section{Conclusões}

Este estudo demonstra e reforça a necessidade de uma Ética Ambiental para América Latina e Caribe que possa partir do enfrentamento de questões centrais que mitigam a vida em nosso continente. Nesse sentido, além de recuperar a reflexão sobre a o sentido da ética cria condições para pensarmos o contexto do COVID-19 e o grande agravamento de problemática que vivenciávamos numa América Pré-COVID-19. Enquanto esforço ensaístico, após revisitarmos alguns autores ousamos na proposição de escolhas que necessitamos fazer no sentido de garantia de vida na América Latina e Caribe. No entanto para tanto é necessário além de denúncias muitas lutas por justiça ambiental em defesa da vida digna. É bom salientar que nossa região possui condições de pensarmos e criarmos outra América possível, para tanto, o primeiro passo necessário consiste na ruptura com 0 modelo de desenvolvimento capitalista e todos os projetos que lhe dão sustentação pela lógica da economia neoliberal e com a adoção do ecossocialismo como alternativa de uma América latina e Caribe mais solidária, coletiva, com maior distribuição de riquezas, novos modos de consumo e fundamentalmente com mais vida. Para isso é, claro que necessitamos ainda nos manter nas muitas lutas pois é por esse viés que desejamos participar de forma ética pela disputa do futuro no mundo pós COVID-19.

\section{Agradecimentos}

Ao Conselho Nacional de Desenvolvimento Científico e Tecnológico (CNPq), pelo apoio financeiro à pesquisa através da Bolsa de Produtividade e a Coordenação de Aperfeiçoamento de Pessoal de Nível Superior (CAPES) através de bolsa de doutorado em andamento. 


\section{Referências}

ABBAGNANO, N. Dicionário de Filosofia. São Paulo: Martins Fontes,2015.

ANAVITÓRIA. Me conta da tua janela. Disponível em: https://www.youtube.com/watch?v=hC0EQGlcbUl . Acesso em 19/05/2020.

ARISTÓTELES. Tópicos. São Paulo: Abril, 1987. (Os pensadores. v.4).

AZEVEDO, F.W. América Latina: 700 povos indígenas estão em sério risco de serem extintos. Disponível em: http://www.ihu.unisinos.br/598791-americalatina-700-povos-indigenas-estao-em-serio-perigo. Acesso em: 17/05/2020.

BATISTA, I.M.S; MIRANDA, L.M. Os "Hidro negócios" nos rios da Amazônia. Rev. Bras. Hist. São Paulo, v. 39, n. 81, p. 117-139, agosto de 2019.

BOFF, L. Ética e Ecoespiritualidade. Petrópolis, Rio de Janeiro: Vozes, 2011.

BOFF, L. Depois do Coronavirus, 2020. Disponível em: $<$ https://jornalggn.com.br/politica/depois-do-coronavirus-por-leonardo-boff/>. Acesso em 19/05/2020.

BORNHEIM, G.A. Introdução ao filosofar: o pensamento filosófico em bases existenciais. São Paulo: Globo, 2009.

CHAUÍ, M. Convite a filosofia.14. ed. São Paulo: Ática, 2010.

ESPINOZA. Baruch de. Pensamentos metafísicos. São Paulo: Abril, 1987. (Os pensadores, v.l 7).

CEPAL, Comissão Econômica para América Latina e Caribe. Observatório COVID-19 en América Latina y el Caribe: Impacto económico y social. Disponível em: <https://www.cepal.org/es/temas/covid-19>. Acesso em 13/05/2020.

COMITÊ AMBIENTAL EM DEFENSA DE LA VIDA. https://www.escrnet.org/member/comite-ambiental-en-defensa-vida. Acesso em 20/05/2020.

DESCARTES, R. Discurso do método. São Paulo: Abril, 1983. (Os pensadores, v.I 5).

GADAMER H-G. Verdade e método: traços fundamentais de uma hermenêutica filosófica. Tradução: Flávio Paulo Meurer. Petrópolis: Vozes, 2002.

GRÜN, M. Em busca da dimensão ética da Educação Ambiental. Campinas: Papirus, 2007.

GRÜN, M. Ética e Educação Ambiental: a conexão necessária. Campinas: Papirus, 1996.

HEIDEGGER, M. Ser e Tempo. Tradução Márcia de Sá Cavalcante. 3 ed. Petrópolis: Vozes, 1989. T.1

HERMANN, N, P. Validade em Educação: intuições e problemas na recepção de Habermas. Porto Alegre: EDICUPCRS, 1999. 
LÖWY, M. Ecossocialismo, democracia e nova sociedade. Disponível e: http://www.ihu.unisinos.br/78-noticias/591623-ecossocialismo-democracia-enova-sociedade. Acesso em: 15 de maio de 2020.

OBSERVATÓRIO DE CONFLITOS MINEROS DE AMÉRICA LATINA. Disponível em: https://www.ocmal.org/las-huellas-del-extractivismo-en-losconflictos-medioambientales-y-por-el-agua-en-contexto-covid-19/. Acesso em 11/05/2020.

OBSERVATÓRIO COVID-19 FIOCRUZ. Disponível em: $<$ https://portal.fiocruz.br/observatorio-covid-19>. Acesso em 14/05/2020.

PEREIRA, V. A. Ecología Cosmocena: la redefinición del espacio humano en el cosmos. Jandiekua Revista Mexicana de Educación Ambiental, v. 3, p. 7482, 2016.

PEREIRA, V. A; FREIRE, S. G; SILVA, M. P. da. Ontoepistemologia ambiental: vestígios e deslocamentos no campo dos fundamentos da Educação Ambiental. Pro-Posições, Campinas v. 30, e 20180011, 2019.

PEREIRA, V.A; MALTA, M.C. (Org.). Ontologia da Esperança: Educação Ambiental em tempos de crise. Juiz de Fora: Editora Garcia, 2020. v. 1. 183p.

PEREIRA, V.A. Existências ameaçadas: a Educação Ambiental em tempos de COVID-19. The Brazilian Journal of Development (BJD). Curitiba, 2020. Disponível em: https://doi.org/10.34117/bjdv6n4-337.

PINTO CALAÇA, I. Z.; FREITAS, P. J C.; SILVA, S. A.; MALUF, F. (2018). La naturaleza como sujeto de derechos: análisis bioética de las Constituciones de Ecuador y Bolivia. Revista Latinoamericana de Bioética, v.18, n.1, pp.155171.

SANTOS, B.S; MENEZES, P.M. (Orgs.) (2009). Epistemologias do Sul. Coimbra: Almedina, $532 \mathrm{pp}$.

SATO, M. O mundo será igual se o ser humano não aprender. Observatório da Educação Ambiental - OBSERVARE. Disponível em: https://observatorioea.blogspot.com/2020/05/mundo-sera-igual-se-o-ser-

humano-

nao.html?utm source=feedburner\&utm medium=email\&utm campaign=Feed\% 3A+ObservatrioDaEducaoAmbiental+\%28Observat\%C3\%B3rio+da+Educa\%C3 \%A7\%C3\%A30+Ambiental\%29. Acesso em: 19/05/2020.

SAUVÉ, L. Educação Ambiental: possibilidades e limitações. Educação e Pesquisa, São Paulo, v. 31, n. 2, p. 317-322, 2005.

WORLD HEALTH ORGANIZATION. Coronavirus disease (COVID-2019) situation reports. Disponível em: $<$ https://www.who.int/emergencies/diseases/novel-coronavirus-2019/situationreports $>$. Acesso em 05/05/2020.

LEIBNIZ. G. W. Discurso de Metafísica. Paris: Aiilbier Montuigne. 1945. 